\title{
The Influence of the Process of Globalization on the Mentality of the Traditional Society
}

\author{
Urunova Hamida Umarboevna \\ Candidate of pedagogical sciences, Chair of social sciences \\ Institute of Economy and Trade of Tajik State University of Commerce
}

\begin{abstract}
The article considers the issue about the essence of the worldwide process of globalization and its influence on changing the mentality of the people in traditional societies. The author notes that this influence has several kinds beginning from clash of cultures, fighting to modernization and development of cultures, but as she emphasizes, generally there is a tendency to an unknown concept according to which common values should rule and dominate all over the world. It means that national states have to realize these values in their interior and inferior policy. In her opinion the process of globalization is equivalent to the process of westernization as today globalization is being realized around western values, which can destruct traditions, and spiritual values of eastern countries, including Tajikistan. That is why on this basis the problem of protecting national identity, which is closely connected with the national mentality, is being activated in many societies.
\end{abstract}

Key words: globalization, traditional society, spiritual culture, spiritual values, sociocultural changes 


\section{Introduction}

It is obviously that today cardinal changes which are happening in the society have touched not only the material sphere of person life activity, also they cause change of traditional and spiritual sphere, the peculiarities of stereotypes of behavior of the people in the national societies as well. The problem of rethinking of national mentality in the period of globalization is considered to be actual, as today the process of transformation is going on in many ethical societies, including Tajik society. Its effective and argumentative solution helps not only to exactly identify the essence and content of the spiritual stereotypes of mentality of people, but also it promotes to fix its peculiarities and observe the process of transformation of the national mentality in new social-economic conditions.

Before analyzing the problem of influence of the process of globalization on the spiritual culture and the national mentality of we think that it is necessary to give a short characteristics of globalization as a social -philosophical phenomenon. As we know term "globalization" is taken from French language «global», which means total, something which covers the whole planet. As a social phenomenon globalization is a complex process which covers economic, social, political, spiritual life of people's civilization.

As a scientific concept "globalization" has been widely used by scientists at the end of the last century and has several interpretations. The Russian sociologist Petrov K.P., the author of the work "The concept of social security and the theory of ruling note that

«...for a long time the process of concentration of ruling the productive power of people was going on which is called globalization. It is an objective process and does not depend on our desire. But it is possible to rule every process. Once in the ancient times the Egyptian priesthood saddled it in order to realize its plans it established specific army and all the human history is the process of globalization at all"' . (Petrov K.P. 2004)

According to the confirmation of other researchers the process of globalization started in the period of Columbus when the first great geographical discoveries were made, first charter companies were opened in the XVIth century which were the organizers of the production and exchange in the world scale and the reason of signing the first international documents

\footnotetext{
${ }^{1}$ Petrov K.P. the theory and the practice of ruling, Moscow, 2004 
It is necessary to take the fact into consideration that beginning from 2 decades of the last century the process of interaction and interdependence of the basic spheres of person life activity in ethical societies has been fastened and became global which is considered to be the integral element of human civilization. Undoubtedly the ontological premises of the globalizational processes are rooted in the material basis of person's life and the transformational process which started to happen in the second half of the XX century. In this case the scientific -technical progress has become the basic reason of increasing the productive, technological, military-technical potential of humanity and the reason of arising global problems of modern civilization.

Besides a geographical mastering of regions of the planet by Europeans and Asian people through sailing and development of culture and science of the period of Renaissance also discoveries made by great scientists in the sphere of exact sciences have promoted the process of globalization. Here we can name creating printing machine, television and its quick spreading, mechanic clocks, advancing transport means, man's fly to Space and learning it, creating world Web-Internet and etc. Space-time concentration of the people of the planet has reduced the social distance. In the period of globalization, the framework of social interaction has been widened and the degree of their interdependence has been increased.

Generally, the process of globalization can be defined as the process of creating single world informational, economic, political, law and cultural space which interact and interrelate with each other. In the modern social science, the economic and political aspects of the process of globalization are more investigated. But the cultural aspect of this process is not investigated enough which is difficult to make a scientific analysis. It can be explained so that the interrelationship of global culture and national culture is happening contradictory.

\section{Clash of cultures.}

It should be mentioned that in the modern social science an opinion about clash of two systems as confrontation of two worlds: old, traditional and modern has been widely spread which we think has enough justification. In this framework we mean not the process of acceptability of values in their historical development, but exactly confrontation which leads to political, religious, and cultural conflicts. Finally, these two constructions are very actual and should be disconnected. 
Firstly, it should be noted that in the period of globalization the problem of clash of cultures arises in the traditional societies as globalization causes the problem of contradiction of cultures. Such confirmation is acacceptable according to the conditions of cultures (especially about their spiritual aspect) of the nations of the post-Soviet sovereign states, as Tajikistan where traditionalism and mental traits of the nation are shown distinctly. Tajik society is an example of traditional society where traditional values, customs dominate which regulate the behavior of the people there.

There we can observe a strict gender hierarchy, sustainable stereotypes which define the orientation and the system of values of the people of traditional culture. Mostly the eastern countries are considered to be traditional societies which are characterized by domination of social interests over individual and unchangeableness of traditional stereotypes. Another peculiarity of the traditional societies is that here the regulators of the social relationships are not private actions but accepted from former generations. As for the nontraditional societies it should be noted that showing individual abilities, innovations, unrepeatability, constant changes are its peculiarities. The basic determinant of the nontraditional society is developing informational society which is defined by increasing the role information, knowledge and informational technology and development of electronic democracy in social life.

A member of nontraditional society believes in his individual abilities, appreciates independence and personal initiation, and the society in its turn supports them. Making a comparative analysis of the traditional and no-traditional societies it is possible to formulate the problem of clash of two worlds which arises in the period of globalization. Collectivism faces with individualism, traditionalism with innovations, and sustainability with constant changes which promote destruction of traditions prevailing by centuries. That is why the problem is born and loudly can be seen more in the traditional than in the non-traditional societies. The influence of the process of globalization can be divided into several kinds: as clash, interaction or interrelationship, modernization, confrontation, conflict and others.

\section{The positive impact of the globalization.}

For complete and system analysis of the current socio-cultural changes it is necessary to emphasize first those tendencies which have perspective character. Characteristically trans 
nationality is the basic trait of the process of globalization which brings nations together. To the experts' mind it promotes mutual understanding and enriching the ethical culture of the nations which live in different states, have different political views, and follow different religious convictions. The process of modern globalization can be considered as interaction and interrelation of the cultures and values which have a creative character. The fruits of the clash of cultures can be seen in any sphere of human life where unique objects of beauty and modern national art are created at the result of the combination of the elements of the material and spiritual cultures of East and West. For instance, architectural constructions, containing the spirit of East and West, also modernized national creations and national art, the system of education, medicine, economy which are being developed by innovational methods and others. The western culture having entered to the content of the national culture enriches it and makes it demanding. The national culture gets more value and meaning only then when it is mixed with the elements of the culture of modern. The modern process of globalization is considered to be the factor which reinforce the process of modernization, renewing and bringing the objects to the state responding to the modern demands and norms. Just due to the process of globalization the elements of modernization which are making the life conditions easier and creating the atmosphere of comfort are entering to the space of the traditional society. The power of gravitation of globalist culture is great, the temptation of getting rich is big, the advertising character of the western life style is powerful; all these gravitates the attention of people as an attractor. The traditional society should learn and form the following stereotypes of thinking and behavior of the western culture as, pragmatism and individualism, which idealize an individual freedom and personal initiation, but press collectivistic interests. These basic conditions are necessary to develop civil society and democratic relationship and promote strengthening the material aspect of life which is the fundamental condition in the hierarchy of human needs. But however the members of the traditional society must apply the western format of the behavior for their own and the benefit of their society not harming the basic socio-cultural code. Of course the diversity of the national culture and the process of their integration in single world cultural space can promote different forms of interaction which influences on forming different models of cultural policy. That is why the uniting factor of social life can be interaction of culture and policy which demand its scientific rethinking and 
developing new mechanisms of realization of state policy in the cultural sphere. The "benefit" of the globalization to the cultures which are under its influence is that perhaps for the first time in the whole historical time of its development the member of the national society gets an opportunity to evaluate the meaning of this phenomenon, and is able to revive his spiritual life. In order not to be in the cultural isolation the traditional society is needed to adapt to the new transforming conditions applying new tendencies for their own benefit making with them a constructive dialogue.

\section{The negative influence of globalization.}

The influence of the process of globalization on the spiritual culture of the traditional society has an ambivalent character. Further we continue the analysis of the process of globalization and note that it can destruct many traditions and spiritual values of the eastern societies one of which is Tajikistan. Globalization in the form of westernization is destructing their traditions and values and making them as western. Today these processes are happening around the western culture and that is why the term "globalization" is used as the synonym of the term "westernization". The process of westernization introduces the traditional societies from one hand to the values which are necessary to modernize the society, but from another hand absolute contradictory one to their traditional way of thinking and behavior. The basic problem which arises at the result of clash of cultures is that the member of the national culture overestimates the globalist culture underestimating his own. It consequently leads to the cultural diffusion. For the member of the traditional society the globalist culture is very attractive, seductive because its whole content is based on the economic relationship and interests. It seems to him promising and provokes this desire to get rich. Just this tendency attracts him to adopt a new culture making him to feel an inferiority complex before another culture. Today increasing the number of migration testifies the globalist culture being very attractive, because the members of the traditional society going out the country and being in the labor migration or in learning have to learn the language of the globalist culture and adjust under the format and style of that nation where they are. This cultural process of assimilation has a mass character today. But we cannot absolutely confirm that the mental traits of the members of the traditional societies under the pressure of the globalist culture are being transformed. Their rooted stereotypes of thinking and behavior are saved. For example, today 
Tajik people living in the western countries celebrate the national holiday Navruz, cook sumanak, plov, i.e. they continue keeping their collectivistic relationship between each other. But, unfortunately the collectivistic way of life and the system of relationship gradually is getting the level of nostalgia. The search of life food has made them to be separated from each other, furthermore life shows itself that today it is not beneficial to keep collectivistic binds which is characterized by the low level of poverty and low level of life. That is why the members of the traditional society voluntarily disconnect their collectivistic relationship and promote developing individualism. Collectivism is collapsing and the relationship between people is based not on relative connections, but on the pragmatism interests.

The influence of the process of globalization on the consciousness of the young people especially is being successfully realized as they are just that category of people who because of their age peculiarities and unsustainability of their character and outlook can easily be impacted. Young generation mostly is inclined to receive more the western culture, values and life style than to be devoted to their traditions. Young generation following the traditional norms compulsorily, but as for joining to the globalist culture they do it voluntarily. Today modern young generation tend to learn western languages, wear western clothes, listen western music and at last realize western life style because the globalist culture having introduced new "fashionable" tendencies under the title "fashion" attracts young people. At the result the national culture loses its value and attractiveness, i.e. the process of devaluation of the national culture.

The influence of the process of globalization on the national culture and the mentality of the traditional society can be seen also in other spheres of people's life. One of the strategic approaches of the state policy in our country in the period of globalization is adopting the law "About regulation of parties", the basic purpose of which is to adapt to the modernized tendencies and decrease the level of poverty. According to the law it is prohibited to have big parties which lets people to improve the family budget. Such approach on a state level gradually turns the collectivistic tendencies into individualistic system of relationship. The influence of the process of globalization on the mentality of the traditional society can be shown in the example of changing paternalism into liberalism among young generation. It should be noted that under this influence the level of upbringing, morality, shame of both man 
males and females. We should not forget that modern process of globalization inevitably cause the process of modernization of the society and its transformation where the survival of the national society especially its spiritual culture as the most priority imperative of saving its uniqueness firstly depends on the content of the culture. That is why following 2 principles can provide the effectiveness of the socio-cultural modernization of the traditional societies:

1) Anthroposocial conformity of the transformational processes with the parameters of the socio-cultural code of the national society, where "modernization" and "traditionalization" are considered to be the basic types of it. They interact, correct each other and can comparatively guarantee the harmony of the transformational processes in the national society.

2) The principle of socio-cultural balance which means balance between cultural and social components as the basic condition of sustainability of the society. Its parameters usually hesitate beginning from dominating traditional to the process of modernization. ${ }^{2}$ (Snegovaya, 2007)

It is necessary to emphasize that a creative adoption of the spiritual culture of the western civilization and using them taking the socio-cultural peculiarities of the traditional societies is much more useful than a passive imitation. Of course a threat of losing the national identity of the country can be the result of the influence of the globalization which has a destructive character in the sociocultural space of Tajikistan.

Also it should be mentioned that after the collapse of the Soviet Union and national conflict in Tajikistan led to the spiritual decline which caused a socio-cultural vacuum which was filled by western values. That is in all the new formed states, privately in Tajikistan a new plan of keeping the cultural heritage of the nation was designed.

Among the researchers there is a wide spread confirmation that the process of globalization can absorb the national culture. In fact, in the national cultures need to be similar to the western culture in order to be "heard" by other cultures and develop, as we know assimilation reduces the originality of the culture. But there is no another way as the process of

\footnotetext{
${ }^{2}$ Snegovaya O.A. Globalization as a socio-cultural process. Autoabstarct of the diss. Of the candidate of philosophical sciences. - Rostov -on -Don, 2007.
} 
globalization makes those cultures "heard" which maximally conform to the western culture. At the result nothing will be left about the uniqueness of the national culture. Though the west does not have any requirements towards the national cultures but it is successfully achieving its goals through indifference toward them. However, if to demand being original and not to try to be "heard" the national society can be left interesting only in its space and be isolated from the world community. Naturally in the "park" of the ethical culture the globalist culture is intruding which can easily set its superiority over any national culture. Obviously traditionalism and modern interact with each other, in other words they are two sides of the same process. That is why for marking today globalization processes exactly and for noting that coexistence of synthesis and destruction is not an occasional case and it is impossible to avoid or cancel it, the expert use the term "glocalization".

It cannot be ignored that today the development of the society is going on as a transition from the national to the globalist culture which is naturally. The language of the globalist culture is English, moreover the national currency of the USA -dollar has become the international financial means of purchase and sale of goods. The mass Western culture is swiftly intruding into the cultural space of other nations a liberal-democratic model of society anyway is being adopted as a standard by other nations, a single informational world space is made (Internet, the newest informational and communicational technology) through which the process of westernization of the spiritual culture of other nations is being. In counterweight to it such movements have been appeared as antiglobalists for whom the issue of protecting and keeping the cultural identity and its uniqueness is very demanding. In such situation we should take it easy and try to transfer the spiritual culture of the nation into the working language of the globalist culture and worthily show it to the people, only then the national culture will be saved and free of damage. In the same time, it is not correct to be limited by the boundaries of the national culture, but it is necessary to find the painless way of exit to the world cultural space. As for the Tajik spiritual culture for the best presentation it can do something in the framework of permitted level. 
Of course it will not be a catastrophe if the national culture of the traditional society cannot meet a wide understanding by the western societies. Finally, it is a national culture and should express the peculiarities of the nation. It can and should bring up its people in the framework of the values of this nation. And

"if it is a real culture then a person will be interesting for the world as the universal culture is formed through the cultural identity of nations. ${ }^{4}$,

The strength of the national culture is just in the specific traits of its values as they are the unique way of understanding the world and its meaning.

Thus to our mind the modern process of globalization has definite corrections in the lives of the people of the Central Asia in the following ways:

a) because of not being developed, the economy of the central Asian countries will be in crisis condition that can provoke the further poverty which can hardly be reduced in the nearest future;

b) the amount of the migrants to the countries of near and far abroad will continuously grow, especially to the Russian Federation;

c) according to the prediction of experts because of the technological backwardness of the countries of the Central Asia the realization of the international programs and projects on lowering the level of poverty will have more success.

d) contradiction in geopolitical relationship of the greatest countries of the world (USA, EU countries from one side, Russia, China and Iran from another side) will be strengthened that will negatively influence on the social-economic situation of the countries of Central Asia;

e) for the traditional societies there will be a sharp necessity to adapt to the modern tendencies of the coming from the western countries which can undoubtedly change the mentality of the nation. Of course it will be realized not calmly, more conflicts can be provoked in this field.

${ }^{4}$ Kosichenko A.G. National cultures in the process of globalization // http://www.orda.kz. Electronic informative analytic bulletin. - №№ 8, 9 . 


\section{Conclusion}

Thus modern process of globalization having created similar economic and political structures cause the process of glocalization which means adaptation of the western culture and values to the local traditions of the national societies.

In such situation the problem of protection and propaganda of the national culture will arise. As the process of globalization allows the national societies to select the elements of the western culture so it is possible to make a constructive dialogue with. It goes without saying that it is very important to strengthen the national security of the independent states formed in the post-Soviet space in the Central Asia.

Thus we can come into conclusion that on the basis of the reality the innovational values which are intruding from the western culture to the space of the national society should answer to the code of the national society, otherwise the clash of the cultures can have a painful result. Also if the national society wants its culture not to be under the threat of devaluation it should answer 4 basic criteria: it should be demanding, necessary, competitive, and meaningful.

\section{Acknowledgement}

I want to thanks my consultants Mr. Zohidov O. the doctor of philosophy for providing the background information and discussion, sharing ideas and fruitful communication of issues indicated in this article. 


\section{Reference}

1. Birukova M.A. Globalization: integration and differentiation of cultures // Philosophical sciences, 2000. - № 4. - p. 33-42.

2. Gubanov N.N. Mentality: the essence, regularity of forming, development and functioning inn the society. Autoabstarct of the diss. Of the doctor of philosophy. - M., 2014.

3. Kosichenko A.Г. National cultures in the process of globalization. // http://www.orda.kz. Electronic informative -analytic bulletin. - №№ 8, 9 .

4. Marx., Engels F. German ideology. - M.: Politizdat, 1983. - p. 29.

5. Mitroshenkov O.A. Culture and civilization // Person. Culture. Society. - M., 2003. - V. 2. - p. 219.

6. Snegovaya O.A. Globalization as a socio-cultural process. Autoabstarct of the diss. of the candidate of the philosophical sciences. - Rostov -on-Don, 2007.

7. Haydarov. R.J. The influence of the process of the globalization on the transformation of the Tajik society. Autoabstarct of the diss. Of the doctor of philosophy. - Dushanbe, 2007.

8. Culture: The Diffusion Controversy. - N.Y., 1927.

9. Orlov F.I. Social outgoings of globalization// Sociological investigation, 2001. - № 7. - C. 1322. 